\title{
Effect of Carbon Nanotubes Combined with Hexaphenoxycyclotriphosphazene on the Flame Retardancy of Epoxy Resin
}

\author{
Jitang Zhang ${ }^{1 \mathrm{a}}$, Wanxi Zhang ${ }^{1}$, Jicai Liang ${ }^{1}$, Dongbo Guan ${ }^{1 \mathrm{~b}^{*}}$ \\ ( ${ }^{1}$ College of Materials Science and Engineering, Key Laboratory of Automobile Materials of Ministry of \\ Education, Jilin University, Changchun 130025, PR China) \\ azhangjitang1982@163.com, bguandb2013@163.com
}

Keywords: epoxy resin thermal properties flame retardancy

Abstract:Epoxy resin composites were prepared via in situ polymerization of diglycidyl ether of bisphenol a epoxy monomer and 4,4'-diaminodiphenyl methane, using multiwalled carbon nanotubes and hexaphenoxycyclotriphosphazene as additives. The morphologies of the specimens were investigated using scanning electron microscopy; thermogravimetric analysis was used to study thermal properties. The results showed that carbon nanotubes improved thermal stability of epoxy resin, but hexaphenoxycyclotriphosphazene decreased thermal stability of epoxy resin. Limit oxygen index, UL-94 vertical burning test and cone calorimeter measurements were used to study the flame retardancy of epoxy resin composites. The results indicated that epoxy resin composites containing hexaphenoxycyclotriphosphazene reached UL-94 V-0 rating, and combustion parameters obtained from cone calorimetry were improved.

\section{Introduction}

Epoxy resin with excellent mechanical properties, electrical properties, good adhesion and corrosion resistance and other excellent performances is referring to molecule contains two or more epoxy groups which uses aliphatic, alicyclic or aromatic as main chain, and polymer oligomer which can form thermoset product via epoxide group reactio $^{\mathrm{n}[1-4]}$. As thermoplastic linear polymer most epoxy resin is liquid at room temperature, but it can crosslink with amine, acid anhydride, and other types of curing agent to form insoluble unmelted three dimensional network structure of thermoset products, and shows its inherent excellent properties, due to active epoxy group in the molecular structure.

Limit oxygen index of general epoxy resin in 20 or so, belong to flammable materials, to widen the range of application of epoxy resin, must perform the flame retardant modification of epoxy resin. ${ }^{[5-9]}$ Two kinds of methods can be used as flame retardant of epoxy resin: blending flame retardant modification and chemical reaction modification. Blending modification is a physical mixing method to introduce flame retardant into the curing system. The introduced flame retardant will not attend the crosslinking reaction of epoxy resin. While in chemical reaction modification, flame retardant is a reactant in crosslinking reaction, and introduces the flame retardant elements to the condensate molecules, which has flame retardant effect.

Phosphorus-nitrile is a new type of organic/inorganic hybrid polymer, nitrogen and phosphorus are arranged alternately in the structure and it can be generally divided into linear and circular polyphosphazenes phosphorus-nitrile. Six chlorine ring three phosphorus-nitrile is important intermediates to prepare phosphorus-nitrile-polymeric materials. Usually, the synthetic of ring three phosphorus-nitrile starts from commercial six chlorine ring three phosphorus-nitrile polymer through the nucleophilic substitution reaction with various functional groups, and the six-member-phosphorus-nitrile ring skeleton of it has strong rigidity, good stability, phosphorus and nitrogen synergistic flame retardant performance due to the alternate arrangement of nitrogen and phosphorus on the ring. As is reported, 
phosphorus-nitrile-polymeric materials can be widely used in flame retardant materials, high temperature resistant material, hydrophobic material, and etc., which has a very extensive research and application value.

Carbon nanotube (CNT) has large length to diameter ratio, excellent mechanical properties and thermal stability, which is widely used in the polymer matrix. In recent years, flame retardant effect of carbon nanotubes on polymer has been widely studied. [10,11]

In this work, epoxy resin composites were prepared via in situ polymerization of diglycidyl ether of bisphenol A epoxy monomer and 4,4'-diaminodiphenyl methane, using multiwalled carbon nanotubes and hexaphenoxycyclotriphosphazene as additives. The morphologies of the specimens were investigated using scanning electron microscopy; thermogravimetric analysis was used to study thermal properties. Use limit oxygen index, UL-94 vertical burning test and cone calorimeter measurements to study the flame retardant properties of epoxy resin composites.

\section{Experimental section}

\section{Materials}

Diglycidyl ether of bisphenol A (DGEBA; commercial name, E-51) was commercially supplied by Wuxi Dic Epoxy Co., Ltd., China. The curing agent 4,4'-Diaminodiphenylmethane was supplied by Sinopharm Chemical Reagent Co., Ltd.Hexaphenoxycyclotriphosphazene was obtained from Lanyin Chemical industry co., Ltd.Multi walled carbon nanotubes was supplied by Nanjing XFNANO Material technology co., Ltd.( inner diameter 30-50nm,length 10-20 $\mu \mathrm{m}$ ).

\section{Preparation of epoxy resin composite materials}

A certain quality of epoxy monomers (DGEBA) was taken and heated to $80^{\circ} \mathrm{C}$ in a drying oven, then other packing materials were mixed with it according to table 1 and the mixture was heated up to $150^{\circ} \mathrm{C}$. Stir fully until packing materials completely dispersed in the epoxy monomers to form a uniform system. Then cooled the uniform system to $80^{\circ} \mathrm{C}$, added the curing agent 4,4'-Diaminodiphenylmethane according to stoichiometric ratio(curing agent/ $\mathrm{DGEBA}=0.25 / 1$ ). Finally mixture and reactant were solidified by being poured to mould made from tetrafluoroethylene. Curing process is as follows, $80^{\circ} \mathrm{C} / 2 \mathrm{~h}+150^{\circ} \mathrm{C} / 2 \mathrm{~h}$.

\begin{tabular}{lllll}
\hline Samples & \multicolumn{1}{l}{ Cured epoxy resin (wt.\%) } & HPCTP (wt.\%) & P (wt.\%) & CNT (wt.\%) \\
\hline EP0 & 100 & 0 & 0 & 0 \\
EP1 & 99 & 0 & 0 & 1 \\
EP2 & 91.54 & 7.46 & 1 & 1 \\
EP3 & 87.81 & 11.19 & 1.5 & 1 \\
EP4 & 84.08 & 14.92 & 2.0 & 1 \\
\hline
\end{tabular}

Table 1 Composition of the epoxy resin composites

\section{Characterization of epoxy resin composite material Microstructure}

First sample was frozen under the condition of liquid nitrogen for 24 hours, then use tools to brittle fracture the sample and spray metal on crispy section. Using field emission environmental scanning electron microscope (USA FEI company XL30 ESEM FEG) to observe the microstructure of sample.

Thermo-gravimetric analysis

Using Pyris TGA thermo gravimetric analyzer (PerkinElmer, USA) to analyze thermo-gravimetric properties of cured epoxy resin sample.

\section{The limit oxygen index analysis}

Limit oxygen index analysis of cured epoxy resin sample was measured by JF - 3 type oxygen 
indicator (Jiangning analysis instrument co., Ltd., Nanjing), spline size $125 \mathrm{~mm} \times 12.7 \mathrm{~mm} \times 3.2 \mathrm{~mm}$.

\section{UL - 94 vertical combustion analysis}

Vertical combustion test was performed by the CZF - 6 type horizontal vertical combustion apparatus (Jiangning analysis instrument co., Ltd., Nanjing), spline size $125 \mathrm{~mm} \times 12.7 \mathrm{~mm} \times 3.2 \mathrm{~mm}$.

\section{Conecalorimetry analysis}

Cone calorimeter instrument was used to analyze the flame retardant of cured epoxy resin (Fire Testing Technology Ltd., UK) ,spline size $100 \mathrm{~mm} \times 100 \mathrm{~mm} \times 3 \mathrm{~mm}$.

\section{Carbon residue analysis}

After the vertical combustion experiment, collecting carbon residue, and then sprayed gold processing within the carbon residue on the surface, using field emission environmental scanning electron microscope (USA FEI company XL30 ESEM FEG) to observe the internal structure of the carbon residue.

\section{Results and discussion}

\section{Microstructure of the composite material}

Figure 1 shows scanning electron microscopy (SEM) images for sample EP1. As is shown, the sample section is coarse, fuzzy, this is due to the carbon nanotubes were added to the epoxy resin matrix, when the brittle fracture occurs, the crack can't truncate carbon nanotubes. In addition, the phenomenon that no obvious carbon nanotubes reunion on the section of sample indicates that carbon nanotubes disperse well in epoxy matrix.

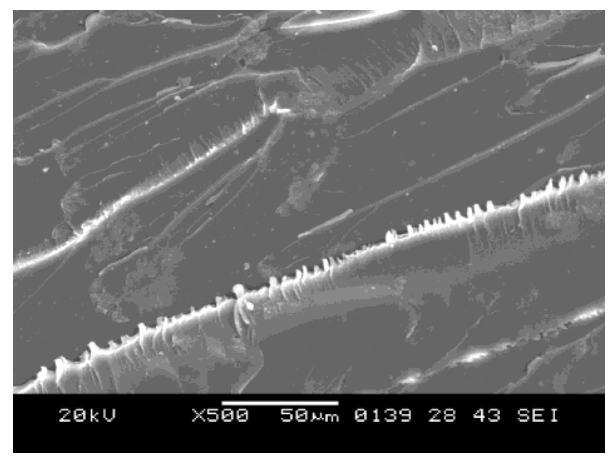

Fig. 1 SEM image of EP1

\section{Thermal performance analysis of epoxy resin composite material}

Figure 2 is the thermo-gravimetric curve of epoxy resin samples under nitrogen atmosphere, detailed data are shown in table 2. The figure 2 shows that after adding carbon nanotubes and hexaphenoxycyclotriphosphazene, thermal decomposition curve of epoxy resin composite material is relatively same with pure epoxy resin, indicates that two kinds of packing material did not change the thermal decomposition mechanism of the epoxy resin. When $1 \%$ of the carbon nanotubes was added, the initial thermal decomposition temperature of EP 1 (mass loss of 5\%) have been improved, this is due to the thermal stability of carbon nanotubes is higher than epoxy resin; because hexaphenoxycyclotriphosphazene is to prepare three phosphorus oligomer with low thermal stability, the thermal decomposition temperature of the phosphorus composites was reduced. The carbon residue amount of EP 0 at $700{ }^{\circ} \mathrm{C}$ is $14.3 \%$, after adding hexaphenoxycyclotriphosphazene, residual carbon amount of composite material has a different degree of increase, especially for EP 4, amount of carbon residue reached $17.6 \%$. The increase of carbon residue has a positive effect on the flame retardant performance. 


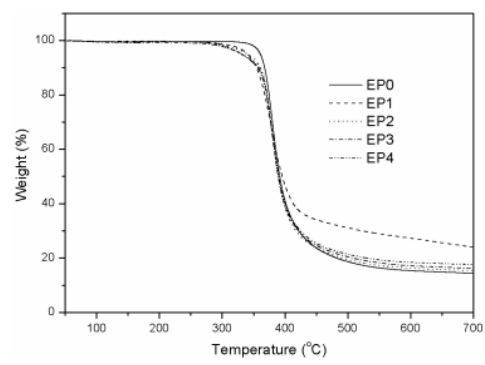

Fig. 2 TGA curves of cured epoxy resin samples

\begin{tabular}{lllllll}
\hline Samples & $\mathrm{T}_{5 \mathrm{w} . \%}\left({ }^{\circ} \mathrm{C}\right)$ & $\mathrm{T}_{10 \mathrm{w} . \%}\left({ }^{\circ} \mathrm{C}\right)$ & Char yield at $700{ }^{\circ} \mathrm{C}(\mathrm{wt} . \%)$ & LOI $(\%)$ & UL-94 & Driping \\
\hline EP0 & 361 & 368 & 14.3 & 22.3 & no rating & Yes \\
EP1 & 368 & 375 & 12.6 & 23.1 & no rating & Yes \\
EP2 & 332 & 361 & 15.4 & 26.8 & V-0 & No \\
EP3 & 330 & 357 & 16.2 & 28.5 & V-0 & No \\
EP4 & 331 & 359 & 17.6 & 29.6 & V-0 & No \\
\hline
\end{tabular}

Table 2 Thermal properties and flame retardancy of cured epoxy resin samples

\section{The flame retardant performance of epoxy resin composites}

Limit oxygen index and vertical burning test is widely used for characterization of combustion performance of polymer materials. Limit oxygen index of EP 0 was 22.3, but there is no level for UL - 94 test, and in the burning process it has a molten drops down; when only add $1 \%$ carbon nanotubes, limit oxygen index increased to 23.1, level of UL - 94 test is still not, which shows that the flame retardant efficiency of carbon nanotubes in epoxy resin is low; After joining hexaphenoxycyclotriphosphazene, the limit oxygen index of the composite increased significantly, and the material have achieved UL - 94V - 0 level, this suggests hexaphenoxycyclotriphosphazene has higher flame retardant efficiency on epoxy resin.

\begin{tabular}{lllll}
\hline Samples & TTI $(\mathrm{s})$ & PHRR $\left(\mathrm{kW} / \mathrm{m}^{2}\right)$ & THR $\left(\mathrm{MJ} / \mathrm{m}^{2}\right)$ & TSR $\left(\mathrm{m}^{2} / \mathrm{m}^{2}\right)$ \\
\hline EP0 & 55 & 1321 & 157 & 7122 \\
EP1 & 58 & 1084 & 115 & 5924 \\
EP2 & 53 & 753 & 103 & 6039 \\
EP3 & 53 & 657 & 103 & 6235 \\
EP4 & 51 & 501 & 100 & 6439 \\
\hline
\end{tabular}

Table 3 Combustion parameters obtained from cone calorimetry.

Cone calorimeter has now become the most important evaluation means in both domestic and international fire test, it can analysis materials in a variety of preset conditions for combustion performance. This method can directly give access to the following data: cone calorimeter (TTI) lighting time, the maximum heat release rate (PHRR) and total heat release (THR), total smoke release (TSR), detailed data are shown in table 3. 


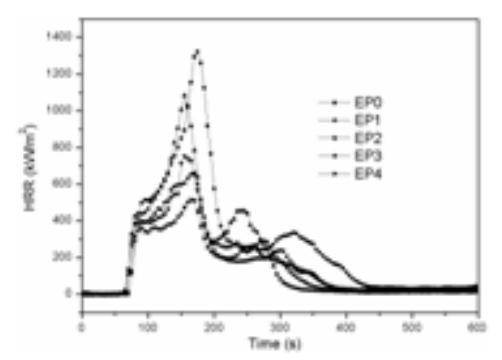

Fig.3 HRR curves of cured epoxy resin samples

TTI for EP0 was $55 \mathrm{~s}$, after adding $1 \%$ carbon nanotubes, the value of TTI increased to $58 \mathrm{~s}$; TTI decreased when adding different content of hexaphenoxycyclotriphosphazene. Curve of heat release rate changing with time for curing sample is shown in figure 3. After lighting pure epoxy resin (EP 0), it combusts rapidly and heat release rate reached a peak of $1321 \mathrm{kw} / \mathrm{m}^{2}$; for EP1, PHRR fell to $1084 \mathrm{~kW} / \mathrm{m}^{2}$, the rate of reduce was $18 \%$; for EP 4, PHRR fell to $501 \mathrm{kw} / \mathrm{m}^{2}$, reduced $62 \%$, showed that with the increase of phosphorus content flame retardant performance of composite materials, is significantly improved. For EP 0 , THR was $157 \mathrm{MJ} / \mathrm{m}^{2}$, after adding flame retardants, THR was also reduced, especially for EP 4 samples, THR fell to $100 \mathrm{MJ} / \mathrm{m}^{2}$, reduced of $36 \%$. Moreover, table 3 shows that the TSR of EP 0 is $7122 \mathrm{~m}^{2} / \mathrm{m}^{2}$, EP 1 (TSR) of $5924 \mathrm{~m}^{2} / \mathrm{m}^{2}$, which shows that carbon nanotubes can suppress smoke to a certain extent.

\section{Carbon residue analysis}

Flame retardant mechanism can be revealed to a certain extent by analysing carbon residue formed after combustion of polymer, and he physical structure of carbon residue has a great influence on the flame retardant performance. After the vertical burning test, carbon residue of sample was collected and its microstructure was observed. Although EP 0 has continuous surface, but there are a large number of cracks and pores on the surface, obviously, this kind of structure does not have thermal stability. For EP 4, almost no cracks and pores exist on the residual carbon surface, and the surface has more compact density, which also shows that epoxy resin forms a kind of thermal stability of carbon layer in the combustion process, spread of flame combustion volatile gas can be inhibited by the carbon layer. In conclusion, the result of carbon residue analysis is consistent with the result of flame retardant.
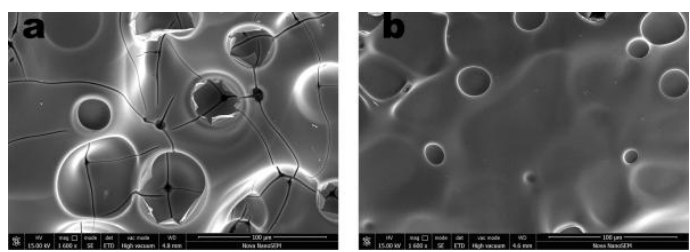

Fig. 4 SEM images of the inside structures of residual chars obtained from the vertical burning tests: EP0 (a), EP4 (b)

\section{Conclusion}

Epoxy resin composites were prepared via in situ polymerization of diglycidyl ether of bisphenol A epoxy monomer and 4,4'-diaminodiphenyl methane, using multiwalled carbon nanotubes and hexaphenoxycyclotriphosphazene as additives. Thermal analysis showed that carbon nanotubes can improve the thermal stability of epoxy resin, hexaphenoxycyclotriphosphazene reduced the thermal stability of epoxy resin, but the amount of carbon residue under high temperature was improved. Pure epoxy resin had no level in UL - 94 test, after joining hexaphenoxycyclotriphosphazene, composite material reachedUL-94 V-0, and flame retardant performance was improved significantly. Cone calorimetry analysis showed that the combination of two kinds of flame retardants reduced heat release rate of the composite material, and hexaphenoxycyclotriphosphazene had more obvious flame retardant effect. In addition, carbon nanotubes had some smoke suppression effect. Carbon residue analysis showed that when the phosphorus content was of $2.0 \%$ of the composite material, the structure of the residual carbon was compact and formed a stable layer which can inhibite the diffusion of flame combustion gas. 


\section{References}

[1] O. Becker, R. Varley, G. Simon, Polymer 43 (2002) 4365-4373.

[2] P.M. Hergenrother, C.M. Thompson, J.G. Smith, J.W. Connell, J.A. Hinkley, R.E. Lyon, R. Moulton, Polymer 46 (2005) 5012-5024.

[3] V.D. Ramos, H.M. da Costa, V.L.P. Soares, R.S.V. Nascimento, Polym Test 24 (2005) 387-394.

[4] Z.K. Chen, G. Yang, J.P. Yang, S.Y. Fu, L. Ye, Y.G. Huang, Polymer 50 (2009) 1316-1323.

[5] Y.L. Liu, Polymer 42 (2001) 3445-3454.

[6] L.A. Mercado, M. Galia, J.A. Reina, Polymer Degradation And Stability 91 (2006) 2588-2594.

[7] C. Kaynak, G.I. Nakas, N.A. Isitman, Appl Clay Sci 46 (2009) 319-324.

[8] E. Kaya, M. Tanoglu, S. Okur, Journal Of Applied Polymer Science 109 (2008) 834-840.

[9] J.K. Duan, C.N. Kim, P.K. Jiang, G.L. Wang, Journal Of Applied Polymer Science 115 (2010) 2734-2746.

[10] P.A. Song, L.H. Xu, Z.H. Guo, Y. Zhang, Z.P. Fang, J Mater Chem 18 (2008) 5083-5091.

[11] N.A. Isitman, C. Kaynak, Polymer Degradation And Stability 95 (2010) 1523-1532. 